\title{
COUPLING PROPERTIES OF CHAIN DRIVE SYSTEM UNDER VARIOUS AND ECCENTRIC LOADS
}

\author{
Ren, W. J.*; Wang, L.*; Mao, Q. H..*; Jiang, S. B. "\# \& Huang, S. \\ ${ }^{*}$ College of Mechanical and Electronic Engineering, Shandong University of Science and Technology, \\ Qingdao, 266590, China \\ ${ }^{* *}$ Shaanxi Key Laboratory of Mine Electromechanical Equipment Intelligent Monitoring, \\ Xi' an University of Science and Technology, Xi'an, 710054, China \\ E-Mail: jiangshoubo@sdust.edu.cn ( ${ }^{\#}$ Corresponding author)
}

\begin{abstract}
The chain drive system is a core subsystem of heavy scraper conveyors. During operation, violent oscillations of fluctuating loads on the chain and uneven loads at the two chain sides are observed, thus intensifying chain wear and even causing chain breakage. The dynamic properties of a chain drive system under various load and eccentric load were discussed thoroughly by combining dynamic and discrete element coupling analyses to improve the reliability of the scraper conveyor. Based on the discrete element method and multibody dynamic theory, a coupling analysis model of a scraper conveyor was constructed, and a simulation analysis on coal conveying process under various load and eccentric load was carried out. Simulation results demonstrate that the transverse vibration of the chain is positively related to coal conveying quantity, whereas longitudinal vibration is negatively correlated to coal conveying quantity. The transverse vibration rate under full loads is $513.62 \%$ higher than that under idle condition, while the longitudinal vibration rate is $53.44 \%$ lower. The effects of coals on transverse vibration and longitudinal vibration of a chain ring are opposite.

(Received in August 2020, accepted in November 2020. This paper was with the authors 3 weeks for 1 revision.)
\end{abstract}

Key Words: Scraper Conveyor, Dynamic Properties, Various Load, Eccentric Load, Coupling Analysis

\section{INTRODUCTION}

A fully mechanized coal mining face is composed of a hydraulic support, a scraper conveyor, a coal cutter, and other auxiliary devices. The scraper conveyor is not only the operational orbit of the coal cutter and the support of the hydraulic support but also the sole coal conveying device. The performance of the scraper conveyor directly determines coal recovery efficiency $[1,2]$. The chain drive system is an important subsystem of the scraper conveyor, and its performance greatly affects the performance of the scraper conveyor [3].

With the expansion of modern coal mining scale, the heavy scraper conveyor is applied more extensively, and the operation of the scraper conveyor is influenced by various complicated working conditions. In ideal coal mining, coals that are cut by the coal cutter are loaded onto the scraper conveyor and then transmitted out of the working face [4]. However, due to uneven coal flows after the coal cutter and randomness during coal loading, the scraper conveyor triggers load fluctuation and uneven load distribution at the two sides of the scraper chain, making the scraper conveyor operate under various load and eccentric load for a long period. The scraper chain suffers serious vibration in coal conveying as a result of the uneven loads, which can greatly affect the chain drive system and accelerate the wearing of the chain ring, causing chain breakage accidents [5]. The scraper blade and chain ring in the chain drive system develop torsional pendulum and increase operational resistance under eccentric load, inducing occurrences of abnormal working conditions such as chain blocking and chain breakage. These abnormal working conditions can substantially affect the stable operation of the scraper conveyor. Therefore, the dynamic properties of chain drive system under various load and eccentric load are explored based on vibration properties to increase the coal 
Ren, Wang, Mao, Jiang, Huang: Coupling Properties of Chain Drive System under Various ...

transmission efficiency of the scraper conveyor and improve the operational stability of the chain drive system.

\section{STATE OF THE ART}

Many scholars have discussed the dynamic properties of the chain drive system in a scraper conveyor. Świder et al. [6] designed a control algorithm that adjusted the motor speed by controlling the voltage frequency, thus controlling the chain speed and improving the operational state of the scraper conveyor. However, they did not discuss the dynamic properties of different running states of the scraper conveyor. Wang et al. [7] simulated the coal transmission of a scraper conveyor by using the discrete element method (DEM) and analysed the influences of chain speed, static friction coefficient, grain size, and pavement angle on coal transmission efficiency. Moreover, they disclosed the variation laws of stress and deformation of the middle groove during coal transmission through a coupling simulation of EDEM and Ansys Workbench. Nevertheless, EDEM cannot simulate the influences of the chain ring on coal transmission efficiency under the occurrence of torsional deformation. Vasylieva et al. [8] optimized the design of the gear drive of a scraper conveyor through the Monte Carlo method and created a simulation model based on IT. Although the simulation efficiency was increased, the influences of optimization of gear drive on the dynamic performances of the chain were not analysed. Philipp et al. [9] measured the contact force among chain rings on the chain by using a small measurement system, discussed the measurement results, and obtained the stress distribution information of the chain. However, they did not measure the dynamic contact force among chain rings under eccentric load. Considering the stability and minimum complexity of a system, Eshchin [10] set up an asynchronous motor-drive control system, organized the oscillation of electromagnetic torque on an axis with changes of loads, and optimized the dynamic properties in startup. However, he only considered the one-way influences of load changes on the motor and did not analyse the improvement of dynamic properties of the chain drive system after startup optimization of the motor. Mazukha and Afonichev [11] designed an improved circuit that was applicable to the scraper conveyor and could protect its circuit upon the occurrence of chain blocking. Wang et al. [12] summarized the dynamic tension among chain rings through the time-varying kinetic analytical method and discussed the crack initiation properties of chain rings under time-varying loads. This dynamic tension could provide references to study chain failure caused by tension changes among chain rings.

The scraper conveyor is a highly coupled system, and the frictional wear of chain ring and chain wheel can substantially influence the dynamic properties of the chain drive system. Based on a wear test of the scraper conveyor under practical working conditions, Wieczorek et al. [13] proved the collaborative influences of environmental corrosion and abrasive materials on the wear of the chain wheel. Jonczy et al. [14] simulated the coal states during transmission using the mixture of hard coal and water through a wear test and studied the frictional properties of the scraper conveyor in real transmission process. Wieczorek [15] investigated the effects of wear of the chain wheel on the chain wheel-ring engagement through a theoretical study and a wear test. However, he did not further discuss the influences of the wear of the chain wheel on the dynamic properties of the chain drive system. These studies analysed the breakage of chain rings, wear of chain wheels, and frictional properties in coal transmission from the perspective of wearing, but none of them discussed the influences of frictional wear on the dynamic properties of the scraper chain during coal transmission.

Xie et al. [16] carried out a simulation analysis on the distribution of four different materials at the chain blocking position of the scraper chain by using the torsional pendulum dynamic model of a scraper conveyor, summarized the influencing law of material distribution on torsional pendulum properties of the chain drive system, and verified the accuracy of 
conclusions by an experiment. Grinschgl et al. [17] proposed a modelling method of chain drive by combining multibody dynamics and the finite element method (FEM), compared simulation analysis and experimental results through a simple double-chain transmission, found that the simulation results agree with the measurement, and verified the reliability of the proposed modelling method. Zhang et al. [18] constructed a dynamic simulation model structure of the scraper conveyor through the FEM. They simulated direct startup under full loads, controllable startup, free halt, and post braking startup by using this model, and obtained the dynamic properties of the scraper conveyor under four conditions. They verified the conclusions by an experiment and corrected the dynamic parameters of the model according to the experimental results. The above studies simulated chain blocking conditions and changing load conditions by applying unilateral loads to multibody dynamic software, restricting chain speed and applying a drag torque onto the driven pulley. However, the abundant contacts between coal particles and chain drive systems during the transmission of the scraper conveyor resulted in violent fluctuation of loads. Hence, restricting running speed or applying loads simply cannot truly simulate the complicated load fluctuation and acting forces of coal particles on the scraper chain in the running process.

The above studies discussed the dynamic properties of the chain drive system from different perspectives. The dynamic signals of the chain drive system of a heavy scraper conveyor cannot be acquired in real time during coal transmission due to the complicated working environment and antiexplosion requirements in mines. Most of existing studies apply a single simulation software and often carry out simulation analyses by applying unilateral loads and restricting chain speed. However, these methods cannot truly simulate the acting force of coal particles on the chain drive system during coal transmission and thereby have great limitations. FEM-DEM coupling analysis can analyse loads, deformation, and stress in mechanical parts that interact with massive materials. However, coupling analyses of the dynamic properties of the chain drive system of a scraper conveyor based on the multibody dynamic software ADAMS and the finite element software EDEM are rare.

Hence, the real contact and collision between coal particles and chain drive system during coal transmission are simulated by constructing a coupling analysis model based on the multibody dynamic theory and DEM. This coupling analysis model is applied to analyse speeds of chain rings, speed of scraper blade, rotational speed, and contact force during real coal transmission under various load and eccentric load, thus obtaining the dynamic characteristic laws of the chain drive system under relevant conditions. This outcome is important for further increasing the coal transmission efficiency of the scraper conveyor and protecting the stable running of the chain drive system.

The remainder of this study is organized as follows. Section 3 introduces the research program and construction of the coupling analysis model and carries out a joint simulation. Section 4 carries out a comparative analysis of speeds of chain ring, speed of scraper blade, rotational speed, and contact force under various load and eccentric load. It also investigates the dynamic properties of the chain drive system under various load and eccentric load from the perspective of vibration velocity and changes of contact forces among chain rings. Section 5 summarizes the conclusions.

\section{METHODOLOGY}

\subsection{Research idea}

A dynamic characteristic test platform cannot be built in a laboratory environment by improving the heavy scraper conveyor with double scraper chains due to the high volume and mass of a heavy scraper conveyor with double scraper chains. At present, numerical simulation analysis is often used to carry out research work $[19,20]$. Therefore, an ADAMS - EDEM coupling 
analysis model was constructed with ADAMS and EDEM. A method to control the joint simulation was proposed by reading the coupling configuration document based on the coupling software Co-Simulation [21]. Based on this method, the dynamic properties of the chain drive system of the heavy scraper conveyor with double scraper chains under various load and eccentric load were investigated.

On the one hand, existing studies on heavy scraper conveyor with double scraper chains generally apply a drag torque onto the driven sprocket to simulate loads during coal transmission. On the other hand, eccentric loading and chain blocking under eccentric load are simulated by restricting the running speed of unilateral scraper blade or applying a relatively strong impact load on one side. However, the scraper blade and scraper chain have relative movements with the coal particles and the middle groove during operation of the scraper conveyor, resulting in complicated contact relations. The scraper blade and scraper chain rings undertake the acting forces of coal particles throughout the running process. Such acting forces change greatly with time, and predicting loads, changes of speed of the scraper chain, and stress changes on the scraper chain and scraper blade during the operation of a scraper conveyor is difficult. Hence, the method of applying a drag torque on the driven sprocket, restricting speed of the scraper chain, and applying impact loads on one side of the scraper blade is too ideal to simulate the real influences of coal conveying loading and eccentric load on the chain drive system of scraper conveyors. In this study, coal particles were generated by the discrete element software EDEM to produce acting forces onto chains [22,23]. The acting forces of coal particles on the scraper chain rings and scraper blades of the scraper conveyor were transmitted to ADAMS by the inbuilt G-Force to realize real-time transmission of acting forces of coal particles, thus achieving reliable simulation results.

Three working conditions, namely, idle condition, $60 \mathrm{~kg} / \mathrm{s}$ coal flow rate, and $130 \mathrm{~kg} / \mathrm{s}$ coal flow rate, were set in the simulation. The variation laws of dynamic properties of the chain drive system with loads throughout the coal transmission were disclosed through a comparative analysis under a specific speed of chain rings. The eccentric load caused by uneven coal loads of a scraper conveyor was simulated by setting a unilateral coal flow rate of $130 \mathrm{~kg} / \mathrm{s}$. Moreover, the dynamic properties of the chain drive system of a scraper conveyor under eccentric load were investigated through a comparative analysis of the specific speeds of the scraper blade and chain ring, rotational speed, and contact force.

\subsection{ADAMS - EDEM coupling analysis model}

In this study, the SGZ764-500 scraper conveyor with double scraper chains was selected as the research object. The simplified model contained 2 chain wheels, 198 chain rings, 9 scraper blades and 3 sections of middle grooves. After SolidWorks modelling, the models were input into the multi-body dynamic software ADAMS and discrete element software EDEM.

Relevant settings were completed in ADAMS and EDEM after model input. ADAMS was used to finish the movement simulation of the chain transmission of the scraper conveyor. EDEM was used to generate coal particles. A coupling relation between ADAMS and EDEM was set up by reading the pre-set coupling document based on the coupling software CoSimulation. On this basis, an ADAMS - EDEM coupling analysis model was built.

Hertz Mindlin (no slip) was selected as the contact model of the coupling analysis model. The model can accurately simulate and calculate the force between particles. The calculation process of particle indirect contact force is as follows [7].

The normal force $F_{n}$ between particles can be calculated by Eq.(1).

$$
F_{n}=\frac{4}{3} E^{*}\left(R^{*}\right)^{\frac{1}{2}} \alpha^{\frac{3}{2}}
$$


where, $E^{*}$ is the equivalent elastic modulus; $R^{*}$ is the equivalent particle radius, which can be calculated from Eq. (2); $\alpha$ is normal overlap, which can be calculated by Eq. (3).

$$
\begin{gathered}
\frac{1}{R^{*}}=\frac{1}{R_{1}}+\frac{1}{R_{2}} \\
\alpha=R_{1}+R_{2}-\left|r_{1}-r_{2}\right|
\end{gathered}
$$

where, $R_{1}$ and $R_{2}$ are the radius of particles 1 and 2 respectively; $r_{1}$ and $r_{2}$ are the position vectors of the spherical centres of particles 1 and 2, respectively.

The normal force $F_{t}$ between particles can be calculated by Eq. (4).

$$
F_{t}=-S_{t} \delta
$$

where, $S_{t}$ is the shear stiffness; $\delta$ is the shear overlap.

\section{RESULTS AND DISCUSSIONS}

\subsection{Simulation results}

The simulation results are shown in Figs. $1 \mathrm{a}-\mathrm{d}$. The scraper chain on the coal falling side is chain a, and the scraper chain on the other side is chain b, as shown in Fig. 1 a. Based on observation of the simulation, all rings on two scraper chains were kept stable throughout the running, without torsion and scraping under idle load. This finding verifies the accuracy of the built models and assures the reliability of simulation results. Under normal coal flow rates (60 and $130 \mathrm{~kg} / \mathrm{s}$ ), all rings on two scraper chains were twisted to some extent, but the torsion degree was too low to influence running of the scraper conveyor. This finding is related to the acting force of coal particles on scraper chains.

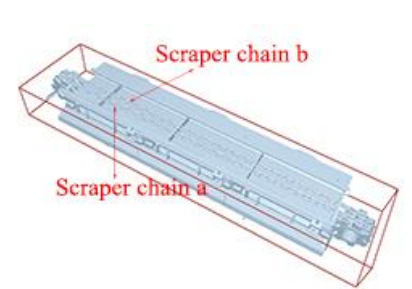

a) idle load

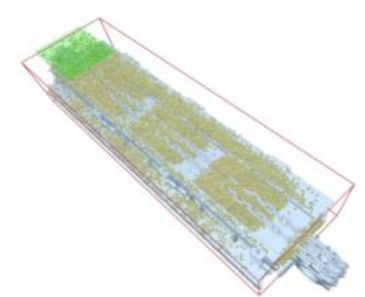

b) $60 \mathrm{~kg} / \mathrm{s}$ coal flow rate

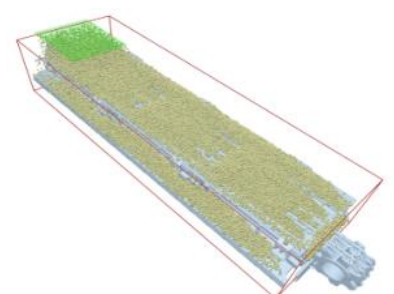

c) $130 \mathrm{~kg} / \mathrm{s}$ coal flow rate

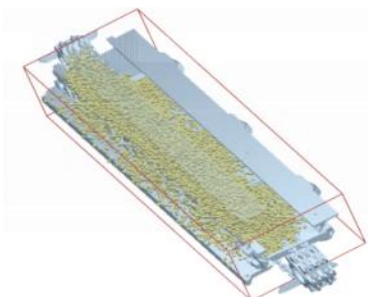

d) $130 \mathrm{~kg} / \mathrm{s}$ unilateral coal flow rate

Figure 1: Simulation results.

Under the normal coal flow rate of $130 \mathrm{~kg} / \mathrm{s}$, the scraper blade showed a slight deflection (Fig. 2). Under the unilateral coal flow rate of $130 \mathrm{~kg} / \mathrm{s}$, scraper blade 2, 3, and 4 were skewed toward the coal falling side to different extents (Fig. 3). The skewness degree of scraper blades was larger under a higher coal flow rate, indicating that the skewness degree of the scraper blade is related to loads. In the simulation analysis of eccentric load, chain rings a12 and a13 broke at $2.85 \mathrm{~s}$ with the increase of loads (Fig. 4). Subsequently, chain rings a89 and a90 broke at $3 \mathrm{~s}$ (Fig. 5).

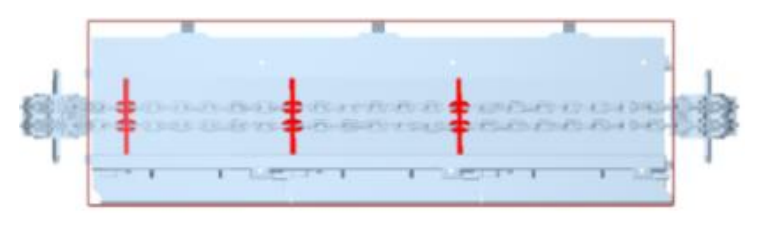

Figure 2: Posture of scraper blades under $130 \mathrm{~kg} / \mathrm{s}$ coal flow rate.

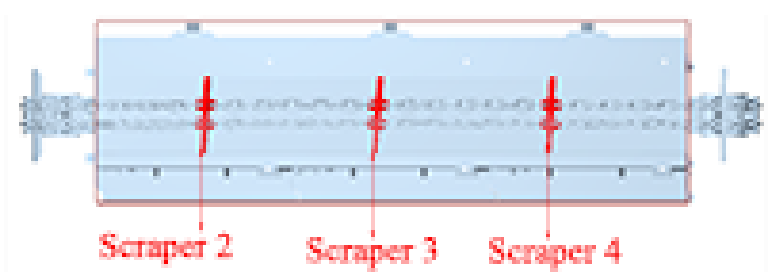

Figure 3: Posture of scraper blade under $130 \mathrm{~kg} / \mathrm{s}$ unilateral coal flow rate. 


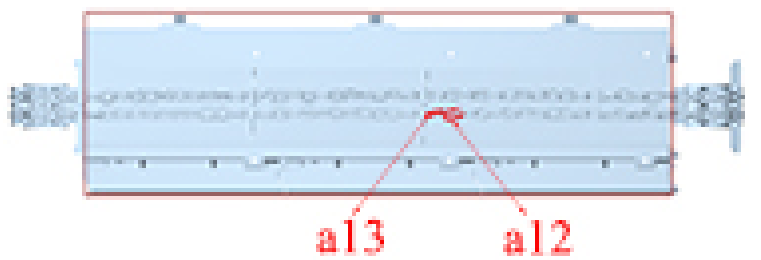

Figure 4: Breakage of chain rings a12 and a13.

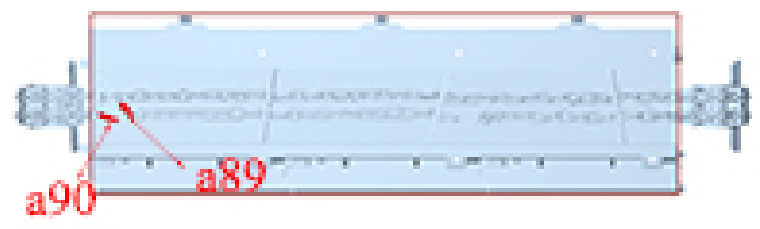

Figure 5: Breakage of chain rings a89 and a90.

\subsection{Dynamic properties under various loads}

Chain rings $\mathrm{a} 1$ and $\mathrm{b} 1$ at two ends of chain $\mathrm{a}$ and $\mathrm{b}$ that are close to two scraper blades were selected (Fig. 6). The x-direction is the direction of the scraper conveyor profile (horizontal), the y-direction was perpendicular to the direction of the middle groove (longitudinal), and the $\mathrm{z}$-direction is the running direction of scraper chain. The variation curves of velocities of transverse vibration and velocities of longitudinal vibration of chain rings a1 and b1 with loads are shown in Figs. $7 \mathrm{a}-\mathrm{f}$. The relation curves between velocities of transverse vibration of the same chain ring and loads are shown in Fig. 8 a. The relation curves between velocities of longitudinal vibration of the same chain ring and loads are shown in Fig. 8 b.

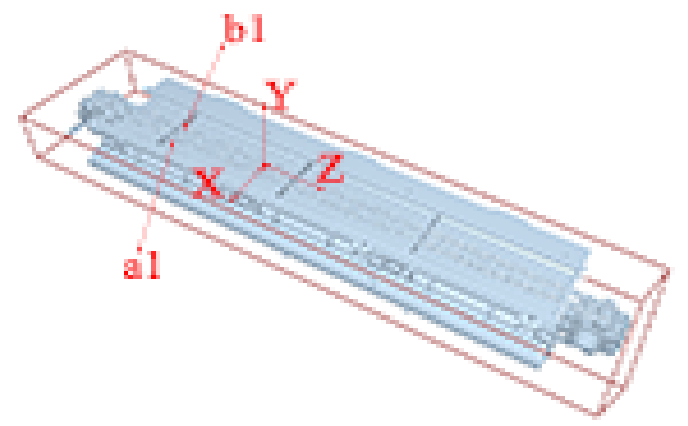

Figure 6: Structure of a specific chain ring.

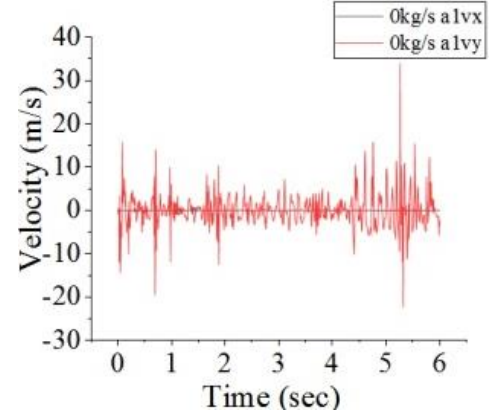

a) No load condition

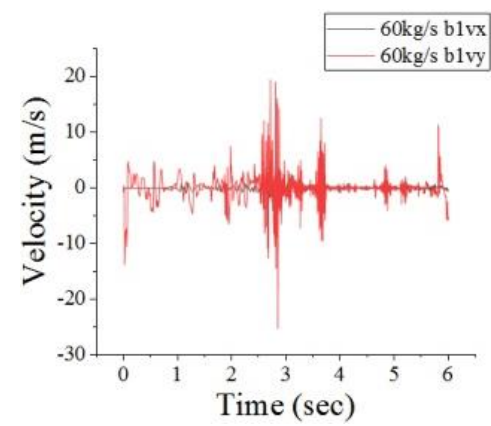

d) $60 \mathrm{~kg} / \mathrm{s}$ coal flow rate

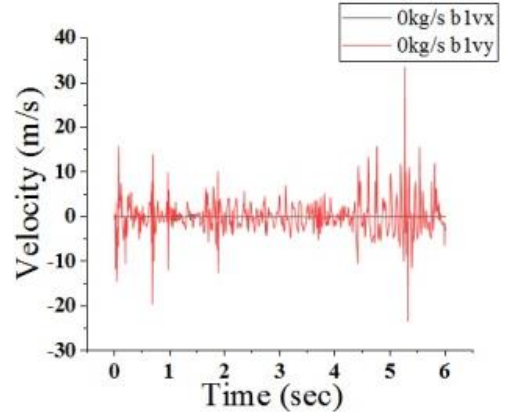

b) No load condition

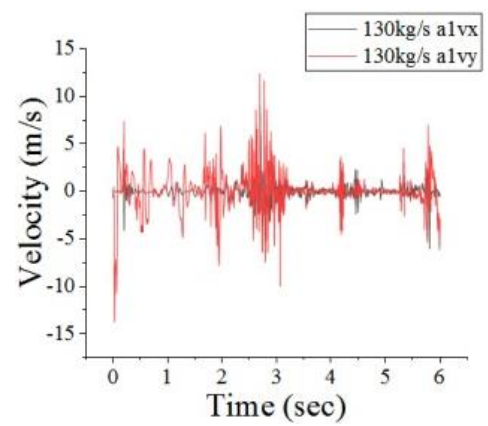

e) $130 \mathrm{~kg} / \mathrm{s}$ coal flow rate

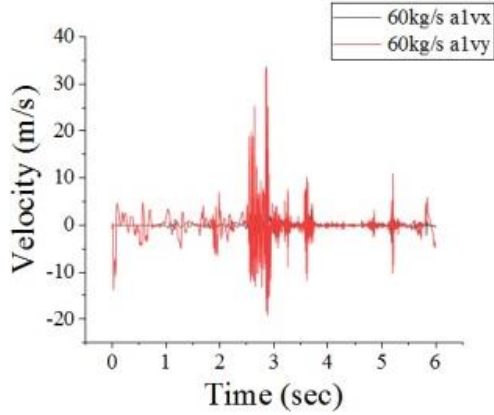

c) $60 \mathrm{~kg} / \mathrm{s} \mathrm{coal} \mathrm{flow} \mathrm{rate}$

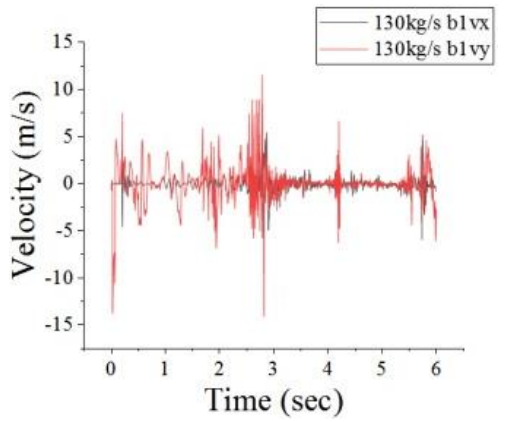

f) $130 \mathrm{~kg} / \mathrm{s}$ coal flow rate

Figure 7: Variation curves of velocity of transverse vibration and velocity of longitudinal vibration of chain rings $\mathrm{a} 1$ and $\mathrm{b} 1$ under different loads. 


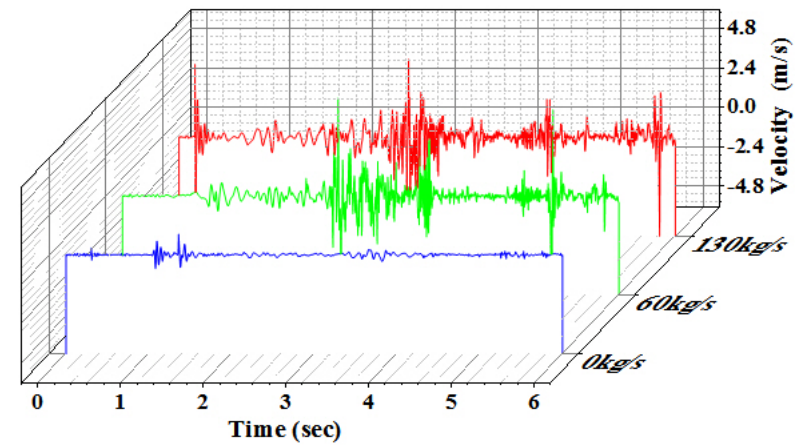

a) Velocity of transverse vibration

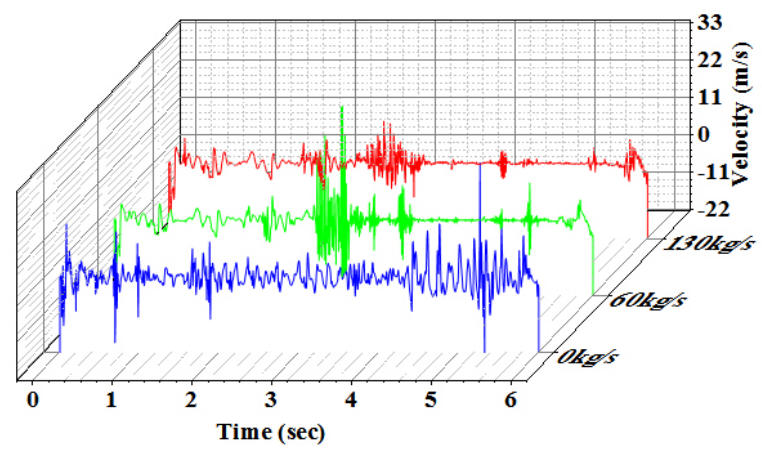

b) Velocity of longitudinal vibration

Figure 8: Variation curves of velocity of transverse vibration and velocity of longitudinal vibration of the same chain ring with loads.

Figs. $7 \mathrm{a}-\mathrm{f}$ show that under idle load and various load, the longitudinal vibration of chain rings was more violent than transverse vibration. When the scraper chain moved in the middle groove, the scraper chain was restricted by the chain wheel. In addition, the middle groove along the profile direction and the middle groove restricted the vibration of the scraper blades along the profile direction, thus restricting the vibration of chain rings in the profile direction. Figs. $8 \mathrm{a}-\mathrm{b}$ show that the velocity of transverse vibration and velocity of longitudinal vibration fluctuated violently at about $2.9 \mathrm{~s}$ under loads. Combining with simulation, shows that coal particles contacted with chain ring a1 at about $2.9 \mathrm{~s}$, indicating that fluctuation of velocity in this section is caused by the acting force of coal particles on chain rings. At the end of coal falling, velocities of transverse vibration and velocity of longitudinal vibration of the chain ring tend to be stable.

Based on further studies, great longitudinal vibration occurs throughout the running process of the scraper conveyor. Middle grooves can remarkably inhibit the transverse vibration of scraper chain. Under sudden changing loads, chain rings at the coal loading positions have transverse and longitudinal vibration behaviours, which intensify the instability of the chain drive system.

The peak and amplitude changes of transverse and longitudinal vibration velocity of chain ring a1 under three working conditions are shown in Figs. $9 \mathrm{a}-\mathrm{b}$.

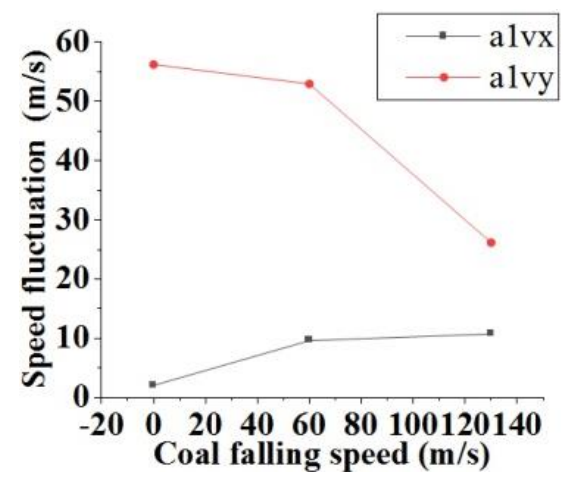

a) Velocity amplitude

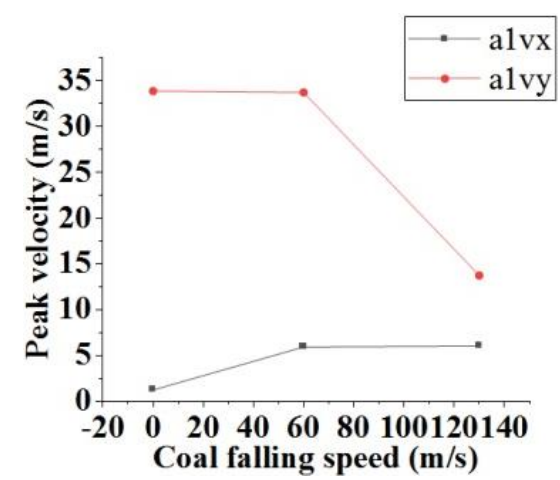

b) Peak velocity

Figure 9: Variations of velocities and amplitudes.

Calculation reveals, that compared with the velocity fluctuation amplitude of transverse vibration, the velocity fluctuation amplitudes of longitudinal vibration wave $26.843,5.49$, and 2.433 times higher under idle load, $60 \mathrm{~kg} / \mathrm{s}$ coal flow rate and $130 \mathrm{~kg} / \mathrm{s}$ coal flow rate, respectively. Under these three working conditions, the peak velocities of longitudinal vibration were $22.113,5.673$ and 2.634 times higher than the peak velocities of transverse vibration, respectively. 
Fig. 9a shows that the velocity fluctuation of transverse vibration of chain ring a1 intensified. The velocity of transverse vibration increased from $2.09476 \mathrm{~m} / \mathrm{s}$ to $10.75903 \mathrm{~m} / \mathrm{s}$, while the velocity of longitudinal vibration decreased from $56.22918 \mathrm{~m} / \mathrm{s}$ to $26.1814 \mathrm{~m} / \mathrm{s}$. Fig. $9 \mathrm{~b}$ shows that with the increase of coal flow rate, the peak velocity of transverse vibration increased gradually from $1.24912 \mathrm{~m} / \mathrm{s}$ to $6.03833 \mathrm{~m} / \mathrm{s}$, while the peak velocity of longitudinal vibration decreased gradually from $33.86785 \mathrm{~m} / \mathrm{s}$ to $13.74725 \mathrm{~m} / \mathrm{s}$. This finding can be interpreted as follows. With the increase of coal mass on the scraper conveyor, the quantity of coal particles and loads increased, such that the contact length $(a)$ between the coal particles and scraper chain along the profile direction increased, as shown in Fig. 10 a. As a result, the probability of collision between coal particles and chain drive system increased, and the acting force of coal particles increased, thus intensifying the effects of coal particles on the chain drive system. The longitudinal thickness of particle piles increased with the increase of coal mass on the scraper conveyor. The velocity of longitudinal vibration of chain rings was restricted, which weakened the vibration of the chain drive system to some extent due to the dead loads of coals onto chains.

According to further studies, coal quantity on the scraper conveyor increases with the increase of coal flow rate. The transverse vibration degree of the chain drive system of the scraper conveyor is positively related to coal quantity, whereas the longitudinal vibration degree is negatively related to coal quantity. The inhibition effect of middle groove weakens with the increase of coal quantity. The incentives of coals to the transverse vibration are strengthened with the increase of coal quantity, and the inhibition of coals against the longitudinal vibration increases with the increase of coal quantity.

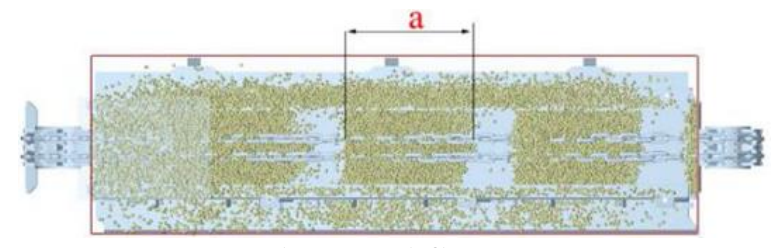

a) $60 \mathrm{~kg} / \mathrm{s}$ coal flow rate

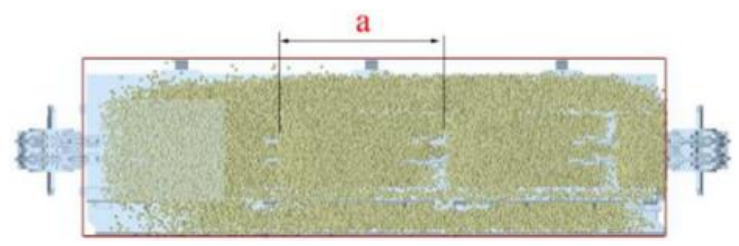

b) $130 \mathrm{~kg} / \mathrm{s}$ coal flow rate

Figure 10: Coal piles on the scraper conveyor under different coal flow rates.

\subsection{Dynamic properties under eccentric load}

The rotational speeds of skewed scraper blades 2, 3, 4, and 9 around $\mathrm{x}$-axis, $\mathrm{y}$-axis, and $\mathrm{z}$-axis in the simulation are shown in Figs. $11 \mathrm{a}-\mathrm{d}$. The rotational speed of four scraper blades around the $\mathrm{x}$-axis $\left(\omega_{x}\right)$ fluctuated more at the breakage of chain rings within 2.8-3.01 s under eccentric loads compared with the rotational speed around y-axis $\left(\omega_{y}\right)$ and z-axis $\left(\omega_{z}\right)$. The peak angular velocities of scraper blade 2, 3, 4, and 9 reached 833.8417, 374.3918, 858.079, and 963.4696 $\mathrm{deg} / \mathrm{sec}$, respectively. Moreover, $\omega_{y}$ fluctuated to some extent in the whole coal transmission, and the fluctuation amplitude increased as the simulation continued. The variation of angular velocity of scraper blade 9 is shown in Fig. 11 d. Nevertheless, $\omega_{x}$ of scraper blade 9 reached the peak at chain breakage, which was the same as the three other scraper blades.

Based on further studies, the acting forces of coals on scraper blade mainly influence the feeding direction of chains during coal transmission, causing rotation of scraper blades around the $\mathrm{x}$-axis. Under eccentric loads, scraper blades undertake uneven stresses and are skewed by the great impact force on the eccentric loading side, thus causing fluctuation of $\omega_{y}$. The broken chain side eliminates the constraint from the scraper chain at the breakage, such that the rotational speed of the scraper blades reaches the peak. Under chain failure of the scraper conveyor, the reciprocating of scraper blade is the major rotational mode, which is the composite rotation around the $\mathrm{x}$-axis and $\mathrm{y}$-axis. Chain rings a12 and a13 broke under eccentric loads. The contacting forces between chain rings a12 and a13 and those between chain rings b12 and b13 at two breakage positions along x-axis, y-axis, and z-axis were extracted. 


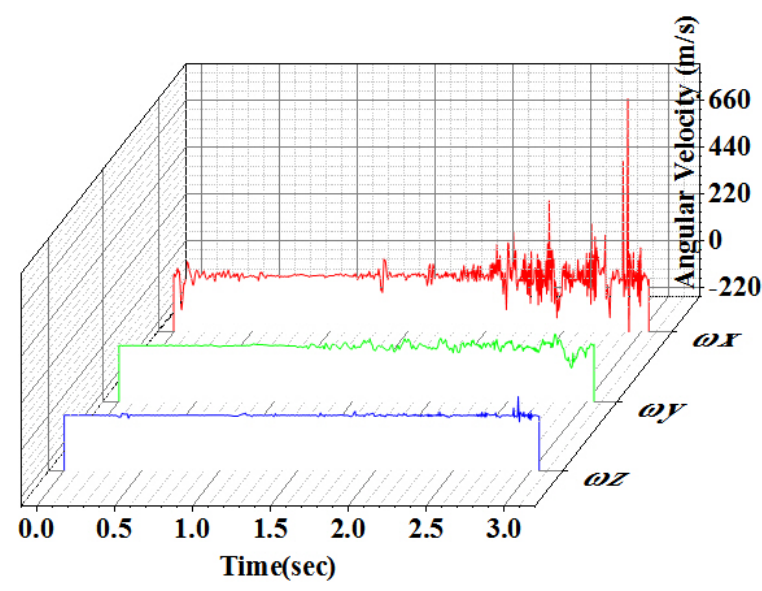

a) Scraper blade 2

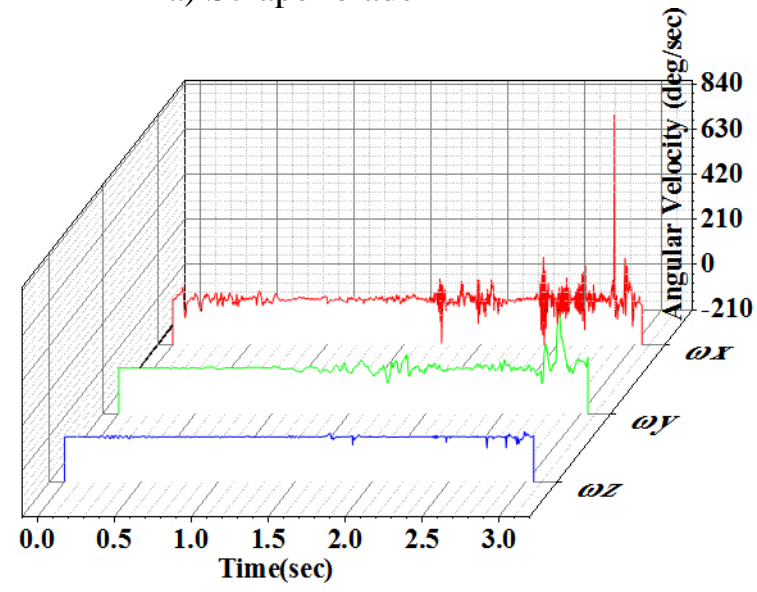

c) Scraper blade 4

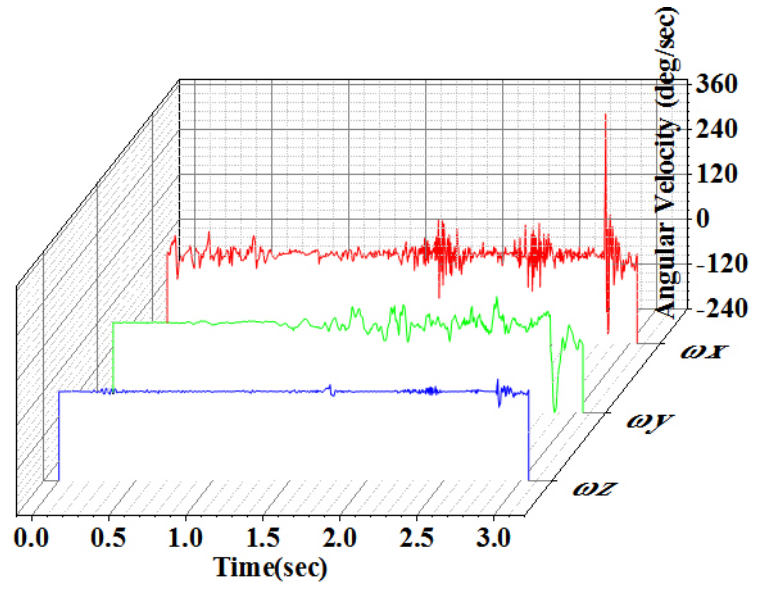

b) Scraper blade 3

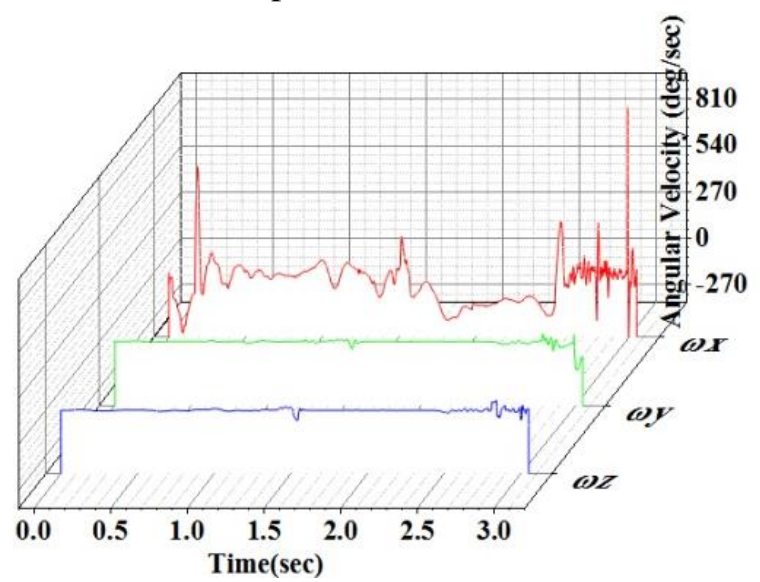

d) Scraper blade 9

Figure 11: Rotational speeds of scraper blades around different axes.

Comparison of contacting forces between chain rings a12 and a13 and those between chain rings b12 and b13 along the profile direction is shown in Fig. 12 a. Comparison of contacting forces between chain rings a12 and a13 and those between chain rings b12 and b13 along the longitudinal direction is shown in Fig. 12 b. Comparison of contacting forces between chain rings a12 and a13 and those between chain rings b12 and b13 along the running direction of scraper blades is shown in Fig. $12 \mathrm{c}$.

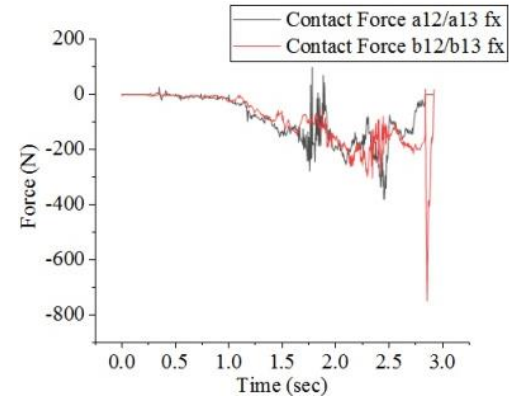

a) Horizontal direction

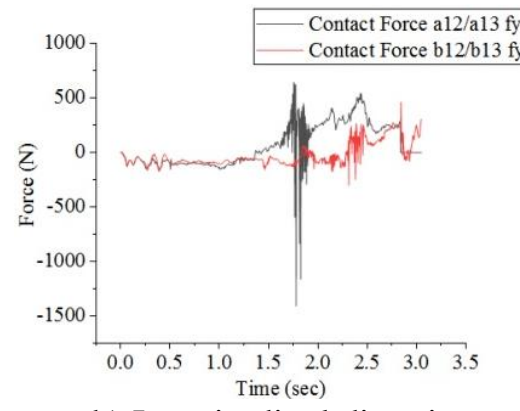

b) Longitudinal direction

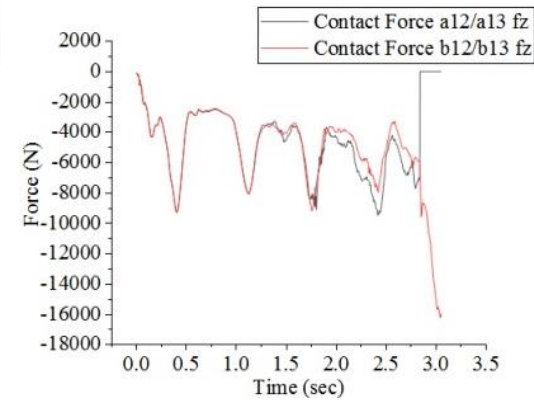

c) Ring running direction

Figure 12: Comparison of contacting forces at chain breakage positions.

Figs. $12 \mathrm{a}-\mathrm{c}$ show that the contacting forces along $\mathrm{x}$-axis, $\mathrm{y}$-axis and $\mathrm{z}$-axis changed suddenly to 0 at the chain breakage, which conforms to the practical chain breakage condition. Moreover, the transverse and longitudinal contacting forces along the heavy loading profile fluctuated more violently at $1.68 \mathrm{~s}$ compared with that on the light loading side. Combining the 
simulation found that coal particles began to contact with chain rings a12 and a13 at this moment, and coal particles impacted onto the scraper chain, thus triggering violent fluctuations of the transverse and longitudinal contacting forces. In the beginning of the simulation, variation curves of contacting forces between chain rings along $\mathrm{x}$-axis, $\mathrm{y}$-axis, and $\mathrm{z}$-axis were consistent, and the contacting forces between chain rings on two chains differed slightly. As the simulation continued, the contacting forces between chain rings on two chains changed, that is, contacting forces between chain rings on the heavy loading side increased considerably and fluctuated more violently. Figs. $12 \mathrm{a}$ and $12 \mathrm{c}$ show that the transverse and longitudinal contacting forces between chain rings b12 and b13 at the same position of the nonbreaking side increased quickly after chain rings a 12 and a13 broke. The peak contacting forces along the $\mathrm{x}-$ axis, y-axis, and z-axis reached 748.5392, 460.8701, and 9465.472 N, respectively, because the scraper blades drove the movement of the coal particles along the running direction of scraper chain, which is the main stress direction. Hence, the peak contacting force along the running direction of scraper chain is the highest.

According to further studies, coal loading may generate large contact forces between chain rings along the $\mathrm{x}$-axis and $\mathrm{y}$-axis, but the contact forces along the $\mathrm{z}$-axis are influenced slightly. Under low eccentric loads, contacting forces between rings on two chains are equal given a small load difference at two sides of the scraper chain. The relatively low eccentric load hardly influences the safety operation of the scraper conveyor. With the increase of eccentric loads, contacting forces between chain rings on the heavy loading side increase significantly, which may generate great safety risks.

\section{CONCLUSIONS}

An ADAMS -EDEM coupling model is constructed to simulate the coal transmission processes under these two working conditions and study the dynamic properties of the chain drive system of the scraper conveyor under various load and eccentric load. On this basis, variation curves of moving speed, rotational speed, and contacting force of chain rings and scraper blades are gained. Several major conclusions could be drawn:

(1) The fluctuation amplitude of the transverse vibration of the scraper conveyor along the profile direction is positively related to coal quantity, whereas the fluctuation amplitude of the longitudinal vibration is negatively correlated to coal quantity. Coals can intensify the transverse vibration along the profile direction of scraper conveyor but can substantially inhibit the longitudinal vibration.

(2) Under coal loads, coals can remarkably influence the transverse contacting forces and longitudinal contact forces between chain rings but slightly affect the contacting forces along the running direction of the scraper chain.

(3) Eccentric loads can remarkably influence the running posture of scraper blades. With the increase of eccentric loads, the contacting forces among chain rings on the heavy loading side along the y-axis and z-axis increase substantially compared with those on the light loading side. However, the contacting forces along the z-axis change slightly.

(4) Load fluctuation intensifies the vibration of the scraper chain. Changing load condition and eccentric load adversely affect the stable operation of the scraper chain and decrease the coal transmission efficiency. Moreover, the scraper chain is twisted due to uneven loads, and the contacting forces among chain rings become more complicated and may even cause chain failure.

The variation curves of movement speed, rotational speed and contacting forces of specific chain rings and scraper blades are gained from simulation of coal transmission under these two working conditions based on the ADAMS - EDEM coupling model to discuss the dynamic properties of the chain drive system of the scraper conveyor under various load and eccentric 
load. Moreover, the results are compared with simulation analysis based on a single software, and a joint simulation is performed using the ADAMS - EDEM coupling model. This model can reproduce the real various load and eccentric load better through simulation. However, the scraper conveyor is a highly coupled system. The influences of all scraper conveyor systems on the chain drive system cannot be reproduced through simulation due to the limitations of current hardware conditions. Hence, a simulation model that conforms to practical working condition better must be found to obtain more accurate results.

\section{ACKNOWLEDGEMENT}

This work was supported by the National Natural Science Foundation of China (Grant No. 51674155); Shandong Provincial Natural Science Foundation (Grant No. ZR2019BEE066); the Shandong Provincial Key Research and Development Project (Grant No. 2019SDZY01); the Project of Shaanxi Key Laboratory of Mine Electromechanical Equipment Intelligent Monitoring (Xi'an University of Science and Technology) (Grant No. SKL-MEEIM201906); Applied Basic Research Project of Qingdao (Grant No. 19-6-2-68-cg); the Project of Shandong Province Higher Educational Young Innovative Talent Introduction and Cultivation Team (Performance enhancement of deep coal mining equipment).

\section{REFERENCES}

[1] Hoseinie, S. H.; Ataei, M.; Khalokakaie, R.; Ghodrati, B.; Kumar, U. (2012). Reliability analysis of drum shearer machine at mechanized longwall mines, Journal of Quality in Maintenance Engineering, Vol. 18, No. 1, 98-119, doi:10.1108/13552511211226210

[2] Reid, A. W.; McAree, P. R.; Meehan, P. A.; Gurgenci, H. (2014). Longwall shearer cutting force estimation, Journal of Dynamic Systems, Measurement and Control, Vol. 136, No. 3, Paper 031008, 9 pages, doi: $10.1115 / 1.4026326$

[3] Jiang, S.; Lv, R.; Wan, L.; Mao, Q.; Zeng, Q.; Gao, K.; Yang, Y. (2020). Dynamic characteristics of the chain drive system of scraper conveyor based on the speed difference, IEEE Access, Vol. 8, 168650-168658, doi:10.1109/ACCESS.2020.3023551

[4] Gao, K.; Zhang, X.; Sun, L.; Zeng, Q.; Jiang, K. (2020). Complex effects of drum hub forms and structural parameters on coal loading performance, Complexity, Vol. 2020, Paper 7036087, 19 pages, doi:10.1155/2020/7036087

[5] Jiang, S. B.; Zeng, Q. L.; Wang, G.; Gao, K. D.; Wang, Q. Y.; Hidenori, K. (2018). Contact analysis of chain drive in scraper conveyor based on dynamic meshing properties, International Journal of Simulation Modelling, Vol. 17, No. 1, 81-91, doi:10.2507/IJSIMM17(1)418

[6] Świder, J.; Herbuś, K.; Szewerda, K. (2019). Control of selected operational parameters of the scraper conveyor to improve its working conditions, Świder, J.; Kciuk, S.; Trojnacki, M. (Eds.), Advances in Intelligent Systems and Computing, Springer, Cham, 395-405, doi:10.1007/978-3030-15857-6_39

[7] Wang, X.; Li, B.; Wang, S.; Yang, Z.; Cai, L. (2018). The transporting efficiency and mechanical behavior analysis of scraper conveyor, Proceedings of the Institution of Mechanical Engineers, Part C: Journal of Mechanical Engineering Science, Vol. 232, No. 18, 3315-3324, doi:10.1177/0954406217734002

[8] Vasylieva, O. E.; Kuzio, I. V. (2014). Optimization of structural elements of drive gearbox shafts of mine scraper conveyors, Naukovyi Visnyk NHU (Науковий вісник НГУ) - Scientific Bulletin of the NMU (National Mining University), Vol. 2014, No. 3, 37-45 (in Ukrainian)

[9] Philipp, C.; Schütz, M.; Nienhaus, K. (2017). Data acquisition of chain forces during longwall operation by using miniaturised measurement systems, World of Mining - Surface \& Underground, Vol. 69, No. 2, 98-108

[10] Eshchin, E. K. (2019). Variant of reduction the complexity of the control system of the asynchronous electric drive, Russian Electromechanics, Vol. 62, No. 2, 53-60, doi:10.17213/01363360-2019-2-53-60 
[11] Mazukha, N. A.; Afonichev, D. N. (2017). Control circuit of the flow line using the multifunction timing relay, Vestnik - Bulletin of Voronezh State Agrarian University, Vol. 2017, No. 2, 128-131, doi:10.17238/issn2071-2243.2017.2.128

[12] Wang, D.; Zhang, J.; Zhu, Z.; Gang, S.; Xiang, L. (2019). Crack initiation characteristics of ring chain of heavy-duty scraper conveyor under time-varying loads, Advances in Mechanical Engineering, Vol. 11, No. 9, Paper 1687814019880366, 11 pages, doi: $10.1177 /$ 1687814019880366

[13] Wieczorek, A. N.; Stachowiak, A.; Zwierzycki, W. (2018). Experimental determination of the synergistic components of tribocorrosive wear of Ni-Cu-Mo-ausferritic ductile iron, Archives of Metallurgy and Materials, Vol. 63, No. 1, 87-97, doi:10.24425/118913

[14] Jonczy, I.; Wieczorek, A. N.; Podworny, J.; Gerle, A.; Staszuk, M.; Szweblik, J. (2020). Characteristics of hard coal and its mixtures with water subjected to friction, Gospodarka Surowcami Mineralnymi - Mineral Resources Management, Vol. 36, No. 3, 185-202, doi: $10.24425 / \mathrm{gsm} .2020 .133939$

[15] Wieczorek, A. N. (2017). Operation-oriented studies on wear properties of surface-hardened alloy cast steels used in mining in the conditions of the combined action of dynamic forces and an abrasive material, Archives of Metallurgy and Materials, Vol. 62, No. 4, 2381-2389, doi:10.1515/amm-2017-0351

[16] Xie, C. X.; Liu, Z. X.; Mao, J.; Xie, M.; Lu, J. N. (2018). Analysis of torsional vibration characteristics of scraper conveyor under struck-chain condition, Journal of the China Coal Society, Vol. 43, No. 8, 2348-2354, doi:10.13225/j.cnki.jccs.2017.1722

[17] Grinschgl, M.; Reich, F. M.; Abeltshauser, R.; Eder, M.; Antretter, T. (2017). New approach for the simulation of chain drive dynamics with consideration of the elastic environment, Proceedings of the Institution of Mechanical Engineers, Part K: Journal of Multi-Body Dynamics, Vol. 231, No. 1, 103-120, doi:10.1177/1464419316653002

[18] Zhang, D. S.; Mao, J.; Liu, Z. S. (2016). Simulation and experiment on starting and braking of scraper conveyor, Journal of the China Coal Society, Vol. 41, No. 2, 513-521, doi:10.13225/j.cnki.jccs.2015.0356

[19] Krantovska, O.; Petrov, M.; Ksinshkevych, L.; Orešković, M.; Synii, S.; Ismailova, N. (2019). Numerical simulation of the stress-strain state of complex-reinforced elements, Tehnicki glasnikTechnical Journal, Vol. 13, No. 2, 110-115, doi:10.31803/tg-20190417112619

[20] Lacombe, A.; Landon, Y.; Paredes, M.; Chirol, C.; Benaben, A. (2019). Numerical simulation of the reaming process in aluminium 2024-T351 - analysis of the evolution of the material stress state, DYNA, Vol. 94, No. 2, 215-220, doi: 10.6036/8900

[21] Wang, X.; Yang, S.; Li, W.; Wang, Y. (2018). Vibratory finishing co-simulation based on ADAMS-EDEM with experimental validation, The International Journal of Advanced Manufacturing Technology, Vol. 96, No. 1-4, 1175-1185, doi:10.1007/s00170-018-1639-0

[22] Khatibi, F.; Esmaeili, M.; Mohammadzadeh, S. (2017). DEM analysis of railway track lateral resistance, Soils and Foundations, Vol. 57, No. 4, 587-602, doi:10.1016/j.sandf.2017.04.001

[23] Byum, J.-H.; Nam, J.-S.; Choe, J.-S.; Inoue, E.; Okayasu, T.; Kim, D.-C. (2018). Analysis of the separating performance of a card cleaner for pepper harvester using EDEM software, Journal of the Faculty of Agriculture, Kyushu University, Vol. 63, No. 2, 347-354 